\title{
Urgences
}

\section{Tournée autour du pot}

\section{Christian Chazel}

Numéro 27, mars 1990

Images imaginaires

URI : https://id.erudit.org/iderudit/025577ar

DOI : https://doi.org/10.7202/025577ar

Aller au sommaire du numéro

Éditeur(s)

Urgences

ISSN

0226-9554 (imprimé)

1927-3924 (numérique)

Découvrir la revue

Citer ce document

Chazel, C. (1990). Tournée autour du pot. Urgences, (27), 61-62.

https://doi.org/10.7202/025577ar d'utilisation que vous pouvez consulter en ligne.

https://apropos.erudit.org/fr/usagers/politique-dutilisation/ 


\section{Tournée autour du pot Christian Chazel}

J'écris : écrins de vie ou écran, à toute épreuve, entre la vie et moi?

J'essaie d'écrire: je suis donc condamné à décrire la vie.

Un pauvre con, damné, pour un p'tit pain sot - car il y a un hic. La décrire: quelle décrépitude! La décrire aux larmes, la décrire à

gorge déployée, la décrire en coin, du voile (tout au plus)? En fait, surtout la décrire jaune.

Car l'écran est là : écran de nacre, écran de fumée... écran d'arrêt.

Suis condamné à tourner autour du pot.

Voilà le postulat, l'apostolat

Et pourtant la poésie douce... si veloutée.

Mais le poste tue la posologie et rend la poterne.

Poste hérité sans espoir (ou l'inverse).

Et le pot est toujours là: atteindre le but... au but.

L'inaccessible est toile.

Le papier se glace, imperméable à l'encre... il faudrait la jeter. Impossible

Le pot, impossible de le teindre.

Impossible de la teindre, comme celle de ces filles de papier glacé(es) et de leurs appas couchés... seulement sur papier (tout ne finit-il pas au panier, dans la poubelle du palier?). Hantise de la feuille planche du salut.

À défaut, on peut toujours:

- se (le) boucher les (des) ouïes

- se (le) coucher dans un lip(r)ogramme douillet

- se doucher

- loucher de tous ses yeux, vu(es) les circonstances ténues

- se (le) moucher, l'odeur a son ying et son yang

- souche qui est le seul vestige...

... du bois.

Et encore! Ne voilà que des mots, tigres qui n'ont pas pied.

Des mots bien placés, mais qui n'ont pas l'air dits...

Des vies apocryphes sorties... d'aucun secours.

De la vie, il ne reste plus que les zoos. 
62

Il y a manque...

L'inaccessible s'étiole.

... de chagrin.

Le texte, c'est la politique de l'autruche à son apogée.

Ce qui s'impose, c'est d'écrire le pot aux roses.

L'écrit turban de la société du spectacle imité (-maté?).

Chercher un canevas chez le Diable, qui toujours l'emporte, à faux.

L'écriture est à bou $(t)($,$) portant sa croix sans sujets.$

Elle a beau se mettre dans trente-six positions, elle n'en trouve pas une de confortable, pas une possible.

Elle cherche sans cesse le(s) sens, mais n'en trouve aucun:

Elle a mis les sens dessus dessous.

Impossible de transmettre les secrets du pentaGone... avec le Vent!

(Le papier réveille plus de sens que ce qui est écrit dessus !)

LE POT LA GLACE ou... LE GLACE (faut pas confondre).

Elle est bouchée au tu, et moi, j’ai...

À condition que l'épi germe 